\title{
Regulation of red cell life-span, erythropoiesis, senescence, and clearance
}

\author{
Lars Kaestner $^{1 *}$ and Anna Bogdanova ${ }^{2}$ \\ ${ }^{\prime}$ Research Center for Molecular Imaging and Screening, Medical School, Institute for Molecular Cell Biology, Saarland University, Homburg/Saar, Germany \\ ${ }^{2}$ Vetsuisse Faculty, and the Zurich Center for Integrative Human Physiology, Institute of Veterinary Physiology, University of Zurich, Zurich, Switzerland \\ *Correspondence: lars_kaestner@me.com
}

Edited and reviewed by:

Mario L. Diaz, Universidad de La Laguna, Spain

Keywords: erythrocyte, erythropoiesis, senescence, clearance, blood storage, neocytolysis, vesiculation

The number of red blood cells (RBCs) and their properties are optimized by nature for most efficient oxygen delivery from the lungs to hypoxic periphery. Changes in metabolic requirements or environmental oxygen availability quickly translate to modulation of the RBC number, blood rheology, oxygen affinity of hemoglobin, and even of vascular tone. Inability to match the changes in oxygen demand may be fatal and requires therapeutic intervention. The recent advances in the ongoing intensive investigations of the mechanisms in control of regulation of erythropoiesis, RBC maturation and aging, as well as the processes involved in recognition of senescent RBCs and their clearance make up the present volume.

It all starts from within the mesoderm, the fetal liver and from the adult bone marrow where primitive or definitive erythropoiesis takes place (Palis, 2014). Facilitated RBC production may be induced promptly "on demand" in extended oxygen requirements upon ascent to the high altitude and quickly reversed when extra $\mathrm{RBC}$ mass is without benefit any more (Risso et al., 2014). Exercise and professional sport increase RBC turnover and maximize oxygen delivery to the tissues (Mairbäurl, 2013). Maturation and aging of RBCs is accompanied by multiple processes occurring at various rates driving the circulating RBCs from adolescence to senescence within approximately 120 days (Lew and Tiffert, 2013; Lutz and Bogdanova, 2013). The resulting "markers of senescence" are recognized by the macrophages and clearance of RBCs is promptly initiated (de Back et al., 2014). Premature clearance is a hallmark of various disorders associated with anemia. In each case one or multiple markers of senescence appear prematurely. Those include excessive oxidative stress (Mohanty et al., 2014), excessive cation leak with the following dehydration (Wang et al., 2014), decrease in RBC size and loss of RBC membrane through vesiculation (Alaarg et al., 2013), metabolic abnormalities (Vives-Corrons et al., 2013), or following autoimmune diseases (Lutz and Bogdanova, 2013). Blood storage damages RBCs facilitating aging. As a result clearance of transfused cells is dramatically facilitated (Bosman, 2013; Flatt et al., 2014).

The present compilation does not only give an overview of the variety of opinions reflecting the current understanding of the mechanisms of erythropoiesis, aging, and clearance of RBCs. We hope that it also provides the base for future lively discussions of the up-standing problems in this rapidly developing research area.

\section{REFERENCES}

Alaarg, A., Schiffelers, R. M., van Solinge, W. W., and van Wijk, R. (2013). Red blood cell vesiculation in hereditary hemolytic anemia. Front. Physiol. 4:365. doi: 10.3389/fphys.2013.00365

Bosman, G. J. C. G. M. (2013). Survival of red blood cells after transfusion: processes and consequences. Front. Physiol. 4:376. doi: 10.3389/fphys.2013.00376

de Back, D. Z., Kostova, E. B., van Kraaij, M., van den Berg, T. K., and van Bruggen, R. (2014). Of macrophages and red blood cells; a complex love story. Front. Physiol. 5:9. doi: 10.3389/fphys.2014.00009

Flatt, J. F., Bawazir, W. M., and Bruce, L. J. (2014). The involvement of cation leaks in the storage lesion of red blood cells. Front. Physiol. 5:214. doi: 10.3389/fphys.2014.00214

Lew, V. L., and Tiffert, T. (2013). The terminal density reversal phenomenon of aging human red blood cells. Front. Physiol. 4:171. doi: 10.3389/fphys.2013.00171

Lutz, H. U., and Bogdanova, A. (2013). Mechanisms tagging senescent red blood cells for clearance in healthy humans. Front. Physiol. 4:387. doi: 10.3389/fphys.2013.00387

Mairbäurl, H. (2013). Red blood cells in sports: effects of exercise and training on oxygen supply by red blood cells. Front. Physiol. 4:332. doi: 10.3389/fphys.2013.00332

Mohanty, J. G., Nagababu, E., and Rifkind, J. M. (2014). Red blood cell oxidative stress impairs oxygen delivery and induces red blood cell aging. Front. Physiol. 5:84. doi: $10.3389 /$ fphys.2014.00084

Palis, J. (2014). Primitive and definitive erythropoiesis in mammals. Front. Physiol. 5:3. doi: $10.3389 /$ fphys.2014.00003

Risso, A., Ciana, A., Achilli, C., Antonutto, G., and Minetti, G. (2014). Neocytolysis: none, one or many? A reappraisal and future perspectives. Front. Physiol. 5:54. doi: $10.3389 /$ fphys.2014.00054

Vives-Corrons, J.-L., Koralkova, P., Grau, J. M., Mañú Pereira, M. D. M., and van Wijk, R. (2013). First description of phosphofructokinase deficiency in spain: identification of a novel homozygous missense mutation in the PFKM gene. Front. Physiol. 4:393. doi: 10.3389/fphys.2013.00393

Wang, J., van Bentum, K., Sester, U., and Kaestner, L. (2014). Calcium homeostasis in red blood cells of dialysis patients in dependence of erythropoietin treatment. Front. Physiol. 5:16. doi: 10.3389/fphys.2014.00016

Conflict of Interest Statement: The authors declare that the research was conducted in the absence of any commercial or financial relationships that could be construed as a potential conflict of interest.

Received: 26 June 2014; accepted: 28 June 2014; published online: 18 July 2014. Citation: Kaestner L and Bogdanova A (2014) Regulation of red cell life-span, erythropoiesis, senescence, and clearance. Front. Physiol. 5:269. doi: 10.3389/fphys. 2014.00269

This article was submitted to Membrane Physiology and Membrane Biophysics, a section of the journal Frontiers in Physiology.

Copyright $\odot 2014$ Kaestner and Bogdanova. This is an open-access article distributed under the terms of the Creative Commons Attribution License (CC BY). The use, distribution or reproduction in other forums is permitted, provided the original author(s) or licensor are credited and that the original publication in this journal is cited, in accordance with accepted academic practice. No use, distribution or reproduction is permitted which does not comply with these terms. 